\title{
Research on the Performance of a New External Occlusion Device for Pressure Vessel Leakage
}

\author{
Hongwei Yan - Xiong Yang - Xiangrong Hou - Lu Wang- Pengcheng Li \\ North University of China, School of Mechanical Engineering, China
}

Given the advantages and disadvantages of the existing plugging technology, a new type of external sealing device for pressure vessel leakage is proposed, which has the advantages of fast installation speed, small installation resistance, and stronger adaptability to the leakage surface. The connecting rod propulsion mechanism provides power, uses the fluidity of materials in the annular cavity to adapt to the complex curved surface, and carries out real-time monitoring and self-healing of the plugging process. Through the establishment of a finite element model of conventional top pressure plugging and the new type of external sac plugging method, simulation analysis of the leakage point and the pressure distribution around the crack leak has shown that: in the installation process of the new type of external liquid sac plugging device, a pressure-equalizing contact area and a sealing area are formed around the leakage point, and there is no obvious stress concentration phenomenon. When the thickness of the gasket is low, the deformation is uniform, which overcomes the problems of insufficient adaptability of the gasket in the conventional jacking method, and enhances the stability and reliability of emergency plugging.

Keywords: leakage, diversion channel, ANSYS, fluid capsule sealing, adaptive contact

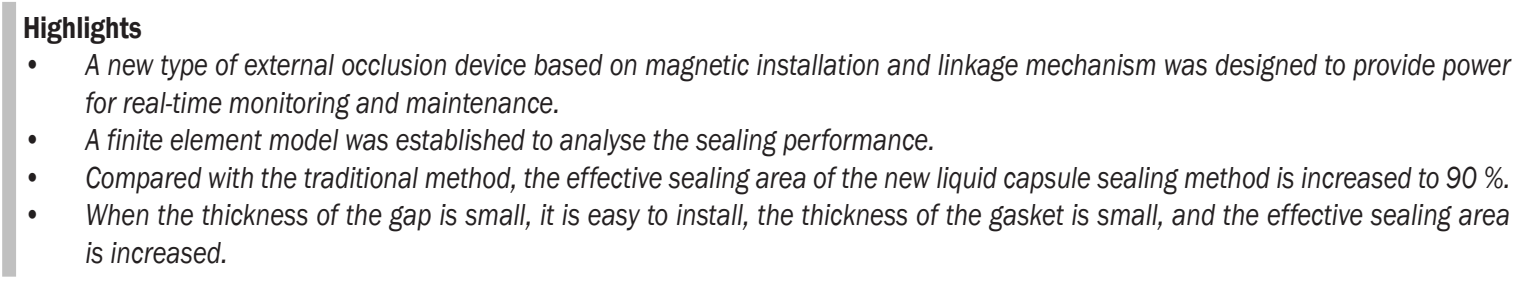

\section{INTRODUCTION}

With the development of the process industry, pipeline transportation has been rapidly developed turned into an economically dangerous medium on a global scale [1] and [2]. Leakage accidents caused by self-defects [3], environmental factors [4] and human factors [5] have occurred, causing huge casualties, environmental pollution, and waste of resources. Therefore, there is an urgent need for a fast, effective, and safe plugging equipment for the treatment and disposal of accident pipelines and storage tanks, the control of dangerous sources, and the reduction of the harm caused by leakage [6] and [7].

In recent years, some emergency blocking repair methods have appeared at home and abroad [8] and [9]. The Furman-ITE company (USA) developed the open hole-plugging device as one of the earliest professional technical companies to solve the problem of pipeline leakage [10]. With the gradual maturity of the technology, the TDW company (USA) has developed a two-way isolation and repair equipment. The system can remotely control and isolate the pipeline with fluid medium [11]. The intelligent intube occlusion developed by Bowie is composed of a traction unit, a plugging unit, and a braking unit, which has the advantages of a simple structure [12]. Due to the different physical and chemical properties of materials and various leakage modes, there are many unforeseen technical problems in the emergency treatment and disposal of leakage accidents at this stage [13] and [14]. In observations of leakage problems, such as holes and cracks in large pipelines and storage tanks, a new type of external plugging device is proposed. Through the simulation analysis of the installation positioning and sealing process of the plugging device, the conclusion is drawn that, the new external plugging device has faster installation speed, smaller installation resistance, and stronger adaptability to the leakage surface in comparison with the conventional plugging method.

\section{STRUCTURE AND PRINCIPLE}

In this paper, a new external sealing device is proposed to address the leakage problems such as holes and cracks in large pipelines and storage tanks. The design indexes of the device are shown in Table 1.

The new sac-sealing device primarily comprises a permanent magnet module, a universal joint, a beam, a propulsion mechanism, and a plugging component. The device uses magnetic adsorption to locate the 
leak. The strong magnetic force generated by the two permanent magnet modules is used to install and fix the device on the work surface to achieve the positioning and installation of the blocking device. The permanent magnet module is connected with the beam through the universal joint to form the staticbearing structure of the blocking device, which can be rotated around the hinge to adapt to the installation requirements of the sealing surface with different radius of curvature; thus, the adaptability of the device is enhanced to some extent. The two propulsion mechanisms are installed between the beam and the blocking assembly. The thrust generated by the selfmotor is used as the power. The sealing assembly is pressed against the leakage sealing working surface to perform the sealing operation. The model of the occlusion device is shown in Fig. 1.

Table 1. Design index of external occlusion device for pressure vessel leakage

\begin{tabular}{clc}
\hline $\begin{array}{c}\text { Serial } \\
\text { number }\end{array}$ & \multicolumn{2}{c}{ Design index } \\
\hline 1 & Pipe diameter [mm] & $\geq 500$ \\
\hline 2 & $\begin{array}{l}\text { Minimum radius of curvature of } \\
\text { elbow [mm] }\end{array}$ & $\geq 250$ \\
\hline 3 & Under maximum pressure [MPa] & $1.6 \leq P<10.06$ \\
\hline 4 & Leakage rate of leakage port [kg/s] & 0.08 \\
\hline 5 & Equipment capacity [kg] & 12 \\
\hline 6 & Two magnets load bearing [kg] & 2000 \\
\hline 7 & $\begin{array}{l}\text { Effective treatment of maximum } \\
\text { crack size [m²] }\end{array}$ & 0.00006 \\
\hline
\end{tabular}

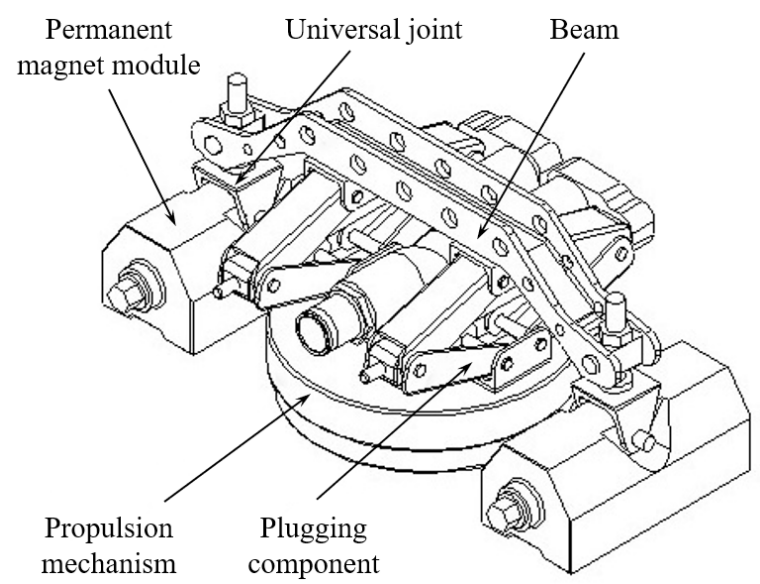

Fig. 1. Schematic diagram of the plugging device mode

When a leak occurs, the first task is to determine the shape or location of the leak. The magnetic force of the two permanent magnet modules is closed by the magnetic switch, the flow guiding channel of the blocking assembly is aligned with the leakage point, and the screw on the universal hinge is adjusted to find the suitable mounting position of the permanent magnet module. Then, the magnetic force of the two permanent magnet modules is turned on, to be adsorbed on the wall of the pipe around the leaking point, and the installation and fixing of the blocking device are completed. Finally, two propulsion devices are started (both synchronous and asynchronous according to the blocking condition) to push the plugging component to the blocking working surface.

During the process of contacting the sealing surface of the plugging device with the tube wall, the fluidity and pressure transferability of the fluid material in the annular chamber are utilized to convert the concentrated load loaded on the housing by the propulsion mechanism into the internal pressure of the fluid in the chamber, which is applied vertically, which allows the pressure load on the plugging surface to be evenly distributed. In this way, the phenomenon of stress concentration caused by local extrusion of sealing cushion in conventional top pressure plugging technology can be avoided [15].

The leak detection system in the occlusion device can monitor the pressure of the fluid in the cavity. After reaching a predetermined plugging pressure, the propulsion mechanism stops moving; the screw selflocking thus maintains a stable plugging pressure. At this moment, the harmful substances leaked into the emergency diversion pipe connected to the diversion channel, and the electromagnetic valve can also be installed at the expansion interface to close the valve to complete the sealing operation.

A sound wave collector (which can also monitor small leaks) is installed at the expansion interface. After the plugging is completed, the flow state of the fluid in the pipe and the plugging state of the plugging device are monitored in real time [16] and [17]. If the plugging fails, the shape of the leak is characterized by the acoustic signal of the fluid; a command is then issued to the propulsion mechanism to enhance the plugging pressure to block the operation again [18].

\section{INSTALLATION AND POSITIONING ANALYSIS}

This paper establishes the common hole leakage and crack leakage models in pipeline and storage tank leakage accidents.

\subsection{Principle Analysis}

The new type of liquid bag outer plugging device uses a permanent magnet module similar to a permanent magnet jack to complete the installation 
and positioning process. During the plugging process, sufficient pressure must be applied to prevent the internal pressure of the leaking fluid from causing the plugging device to fall off. No bolts are required during installation. The minimum radius of the pipeline curvature that the new external plugging device is adapted to is $250 \mathrm{~mm}$.

When the pipeline is corroded by material or impacted by an external force, perforation or cracks often occur [19] and [20]. In such cases, it is necessary to seal the leakage point. Due to the high internal pressure and high energy density of the leaking materials at most of the leakage points, a Bernoulli equation is selected to express the fluid energy at the leakage point [21] and [22]. The plugging mainly deals with the fluid state at the leakage point; there will be no large displacement in the vertical direction. The change in potential energy has little effect on the energy density of the fluid, which can be ignored [23]. Bernoulli's equation can be simplified as follows:

$$
C=p+\frac{1}{2} \rho v^{2},
$$

$C$ is the energy per unit volume of fluid, $p$ is fluid pressure, $\rho$ is fluid density, and $v$ is fluid velocity.

The energy density of the fluid directly determines the difficulty of the plugging operation. The existing external plugging technology is pressed with a sealing material at the leak point to achieve the plugging operation. With the top pressure plugging as an example [24], the sealing process is shown in Fig. 2.

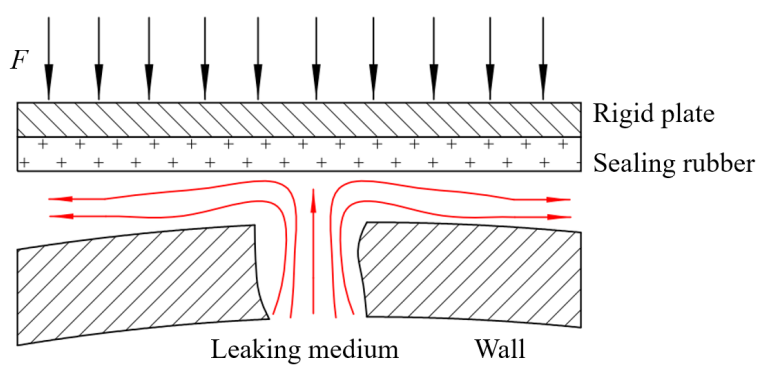

Fig. 2. Schematic of hole leakage pressure seal

When the sealing surface of the occlusion device gradually approaches the leak point, the flow pattern of the leaked material is forced to change. The fluid material ejected from the leaking point enters the crevice formed by the sealing surface of the occlude and the wall of the vessel. The narrowing of the crevices hinders the flow of the fluid, and the flow rate of the material continuously decreases until it reaches zero. In this process, accompanied by the energy loss caused by internal irregular flow [25], Eq. (1) can be rewritten as:

$$
C=p+\frac{1}{2} \rho v^{2}+Q
$$

$Q$ is heat generated by friction during unit volume fluid flow (assuming heat is not transferred)

The main factor affecting the installation of the plugging device is the static pressure $F=p \cdot S$ of the fluid acting on the plugging device [26], which is obtained by the Eq. (2):

$$
\begin{gathered}
F=\int\left[C_{0}-\left(\frac{1}{2} \rho v^{2}+Q\right)\right] d s, \\
C_{0}=p_{0}+\frac{1}{2} \rho v_{0}^{2}, \\
Q=\lambda \cdot \frac{1}{2} \rho v^{2},
\end{gathered}
$$

$F$ is installation resistance, $C_{0}$ is the raw energy density of the leaked material, $S$ is the area of the sealing surface of the plugging device, $p_{0}$ is the pressure of the original fluid in the container, $v_{0}$ is the velocity of the original fluid in the container and $\lambda$ is fluid friction coefficient.

It can be obtained from Eq. (3) that the main factors affecting the installation resistance of the plugging device are:

1. The energy density of the leaking material itself (the pressure and flow rate).

2. The coefficient of flow friction of the leaked material is determined by the shape of the leak and the geometry of the sealing surface of the plugging device.

3. The size of the sealing surface of the plugging device.

As shown in Fig. 2, the material ejected from the leak point collides with the sealing surface that is constantly approaching, and the kinetic energy is converted into static pressure in the impact region, forcing the fluid material to enter the nip. As the thickness of the gap decreases, $\lambda$ gradually increases, the flow rate $v_{0}$ of the material decreases continuously, and the static pressure region at the leak point diffuses into the nip, forming an annular static pressure zone with different gradients around the leak point, and the installation resistance is large, the installation resistance has increased significantly.

In observation of the above problems, the occlusion of the new type of sac-sealing device adopts a diversion installation method, which is installed first and then blocked by a valve to reduce the installation 
resistance of the occlusion device, so as to make the installation and positioning more accurate and reliable. The specific process of implementing the plugging operation is shown in Fig. 3.

During the installation process, most of the fluid material ejected from the leaking point flows out of the flow channel of the occlude, as shown in Fig. 3. Part of the fluid enters the nip, and a small part hits the sealing surface of the occlusion device, which effectively restrains the conversion of the kinetic energy of the fluid material to the pressure energy. The fluid flow rate and static pressure entering the nip are greatly reduced, which further greatly reduces the load on the sealing surface of the occlusion.

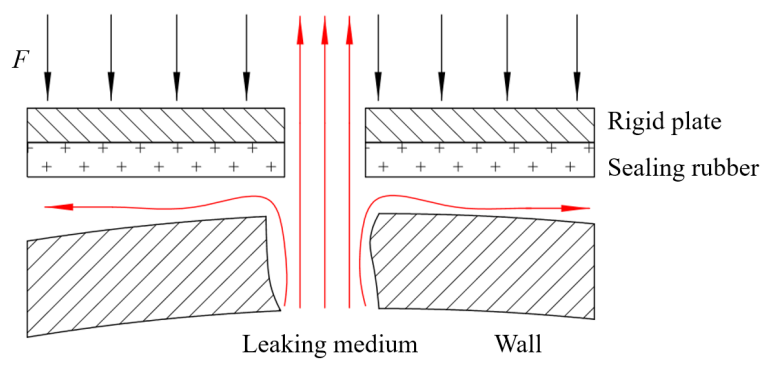

Fig. 3. Schematic diagram of diversion plugging

\subsection{Flow Field Velocity Analysis}

At present, the most common form of leakage in pipelines and tanks is crack leakage [27] and [28]. Two different leak point models, a hole with a diameter of $50 \mathrm{~mm}$ and a crack with a width of $4 \mathrm{~mm}$ and a length of $100 \mathrm{~mm}$, are used to simulate the above method [29]. Both leakage models are based on a cylindrical storage tank with a radius of $3000 \mathrm{~mm}$. The inside of the tank is a methane gas with a pressure of $1 \mathrm{MPa}$, the external pressure is $0.1 \mathrm{MPa}$, and the sealing surface of the occlusion is a circular area with a diameter of $190 \mathrm{~mm}$, and the diameter of the reverse flow passage is $40 \mathrm{~mm}$. Due to the large volume of the tank, the following approximate assumptions can be made: (a) the pressure in the tank is not affected by the leakage; (b) the pressure loss caused by the friction in the vessel after the leakage is ignored. The results of the analysis are shown in the figure below.

The gap between the sealing surface and the outer wall of the tank is $4 \mathrm{~mm}$. The flow field characteristics of the non-conducting plugging device are shown in Fig. 4. The leaked fluid material flows out from the nip, forming a flow field with a high flow velocity $(100 \mathrm{~m} / \mathrm{s})$ on both sides of the crack. The flow field characteristics of the diversion blocking device are shown in Fig. 5. Only a small amount of material flows out of the nip at a relatively low flow rate (56 $\mathrm{m} / \mathrm{s}$ ), and most of the material flows out of the device through the flow-guiding channel. In this way, part of the material can be recovered through the flow guiding channel, the leakage amount of the fluid material in the tank is reduced, the spraying speed of the fluid in the nip is reduced, the influence of the fluid jet on the sealing operation is reduced, and the safety factor is enhanced.

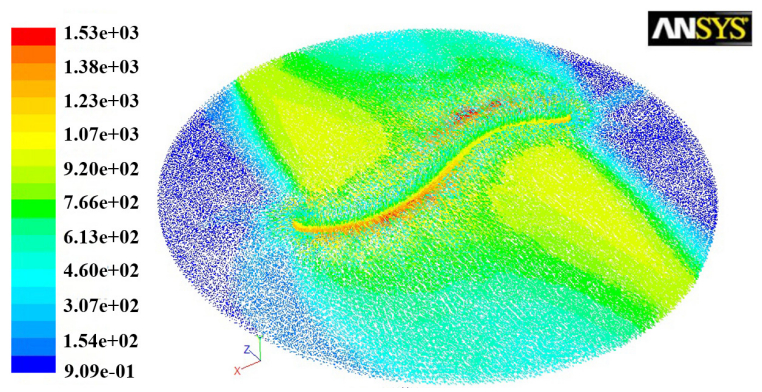

Fig. 4. Flow field vector in the case of no diversion plugging device $4 \mathrm{~mm}$
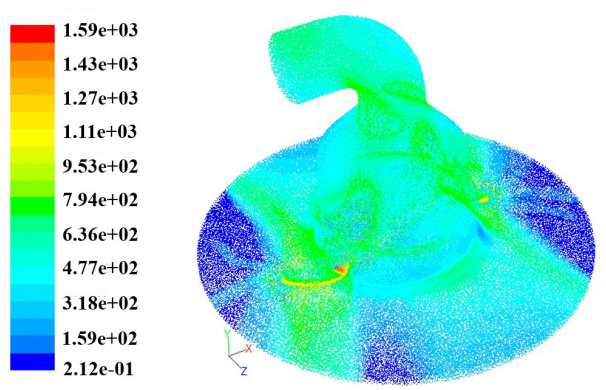

MNYS

Fig. 5. Flow field vector graph of the diversion and closure device with $4 \mathrm{~mm}$

\subsection{Crack Thickness Analysis}

The thickness of the nip affects the ejection speed of the leaked material and determines the ease of sealing operation. The clamping resistance of the two models (step size $5 \mathrm{~mm}$ ) is used as a variable to simulate the installation resistance of the two blocking devices during the installation process. The results are shown in Fig. 6.

During the installation of the plugging device, the mounting resistance is not significantly different between the two plugging methods when the thickness of the gap is large $(>30 \mathrm{~mm})$. In this case, the proportion of the fluid material passing through the flow guiding channel is small, and the influence on the overall flow field is small, and the installation resistance changes of the two occlusions are basically the same. When the thickness of the gap is reduced, the 
fluid motion resistance increases, forcing the material flow in the diversion channel to increase, and the installation resistance shows a difference. Compared with the non-diversion channel, the diversion channel reduces the peak of the installation resistance by nearly $36 \%$.

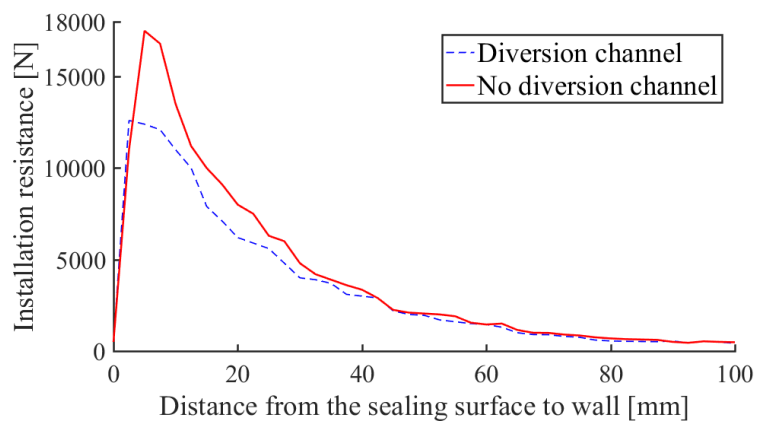

Fig. 6. Comparison of the resistance in the process of crack leakage model

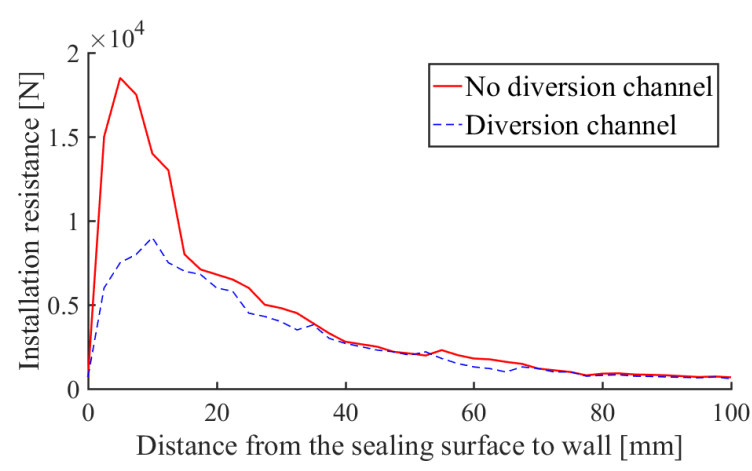

Fig. 7. Comparison of the resistance of the hole leakage model

The same analysis was done for the hole leakage model. The results are shown in Fig. 7. The peak value of the mounting resistance was reduced by nearly $53 \%$. It can be seen that the diversion function is affected by the geometry of the leakage point, and the corresponding diversion channel needs to be designed for the specific leakage form to meet the requirements of the diversion. Similar results were obtained when the medium in the tube was changed from gas to liquid water.

\section{PLUGGING PROCESS ANALYSIS}

This paper compares the sealing process of the device with the conventional top pressure sealing method.

\subsection{Principle Analysis}

Large pipes and pressure vessels are most common in small hole leaks or cracks at welds and are representative. It is necessary to analyse the stress distribution of the plugging device at the weld [30] and [31].

The existing large-scale storage tanks are mostly sealed with the top pressure sealing method. The loading is applied on the rigid body, and the flexible composite rubber is pressed on the sealing working face to form the plugging area [32]. The working principle is shown in Fig. 8.
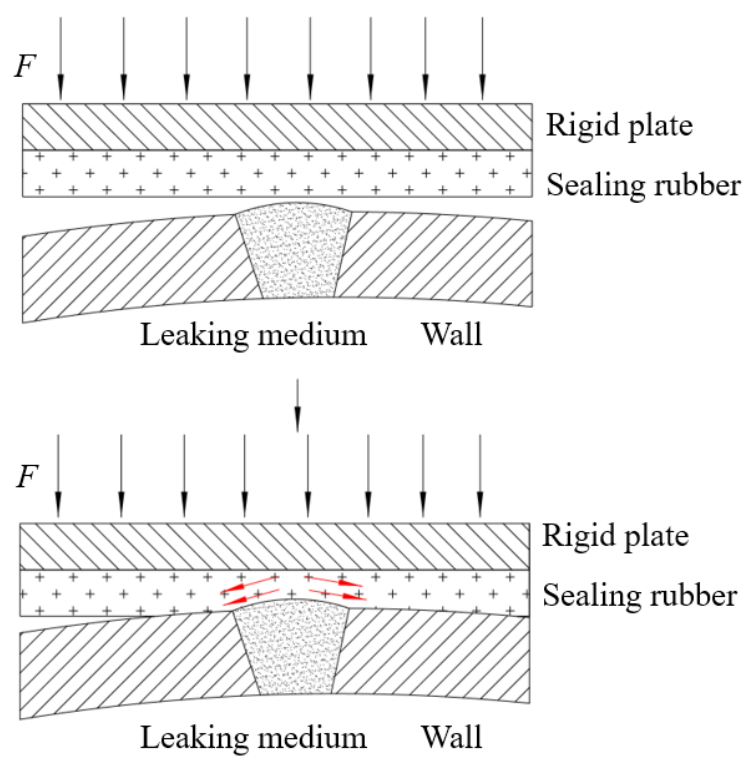

Fig. 8. Principle of common top pressure plugging

When sealing irregular surfaces, such as welds, the sealing rubber gaskets must use their deformation to adapt to the undulating changes of the curved surface. In non-linear large deformation weld, rubber material can be regarded as volume incompressible continuum, and the internal stress state will be uneven during deformation [33]. In the non-linear large deformation weld, the rubber material can be approximated as a volume incompressible flow body, and local flow phenomenon of the internal material occurs during the deformation process. The rubber element has the following stress relationship inside the compression deformation.

$$
\begin{gathered}
\sigma=\frac{E \alpha\left[(1+\varepsilon)-(1+\varepsilon)^{-2}\right]}{3}, \\
\varepsilon=\frac{f}{h},
\end{gathered}
$$

$\sigma$ is internal stress of rubber components, $E \alpha$ is the elastic modulus of rubber components, $\varepsilon$ is the strain of rubber components, $f$ is the shaped variable of 
rubber component and $\mathrm{h}$ is the thickness of rubber component.
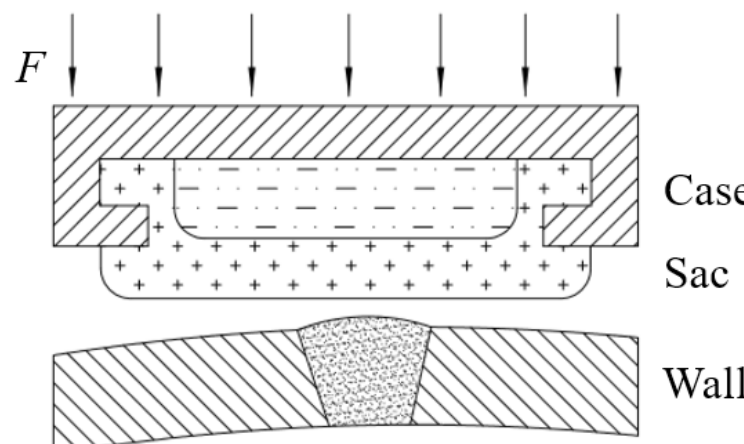

Wall

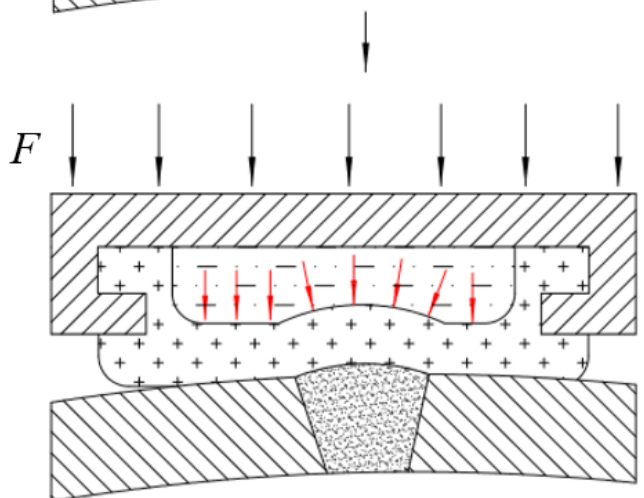

Case

$\mathrm{Sac}$

Wall

Fig. 9. Schematic diagram of loading and sealing of the liquid bag

Rubber materials use their deformation to adapt to the ups and downs of the curved surface, which makes the internal stress state of the material uneven. At the same time, when the material is compressed, it will produce the shear stress to prevent the deformation of the material. The welding seam imposes constraints on the rubber material, which enhances the longitudinal bearing capacity and further promotes uneven stress. To avoid this situation, this article uses the fluid pressure loading method to perform the plugging. The plugging process is shown in Fig. 9.

\subsection{Analysis of Pressure Distribution}

In this paper, the leakage model of the tank weld with the outer wall radius of $3000 \mathrm{~mm}$ is established as the blocked object. The weld height is $5 \mathrm{~mm}$, and the width is $40 \mathrm{~mm}$. There is a crack with a length of $100 \mathrm{~mm}$ on the weld. The conventional top pressure plugging method and the liquid bag plugging method were used for plugging respectively. The plugging pressure load was set at $1 \mathrm{MPa}$, and the sealing gasket material was set as NBR. The simulation results are shown in Figs. 10 and 11.

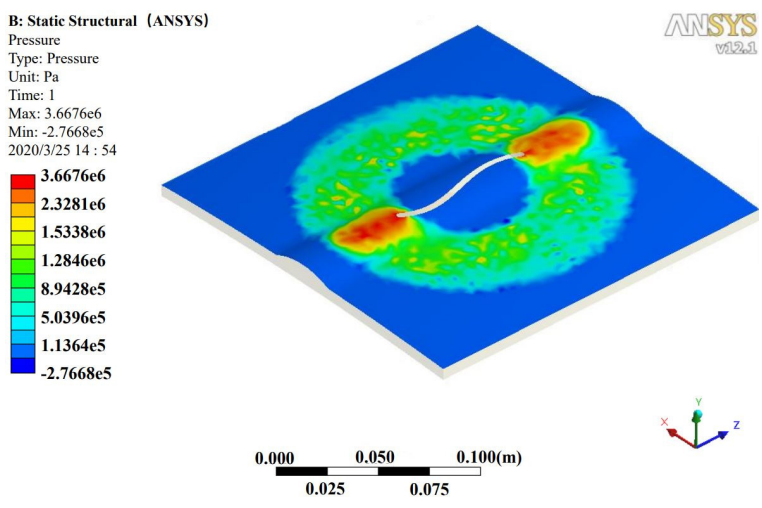

Fig. 10. Sealing surface pressure of conventional sealing method

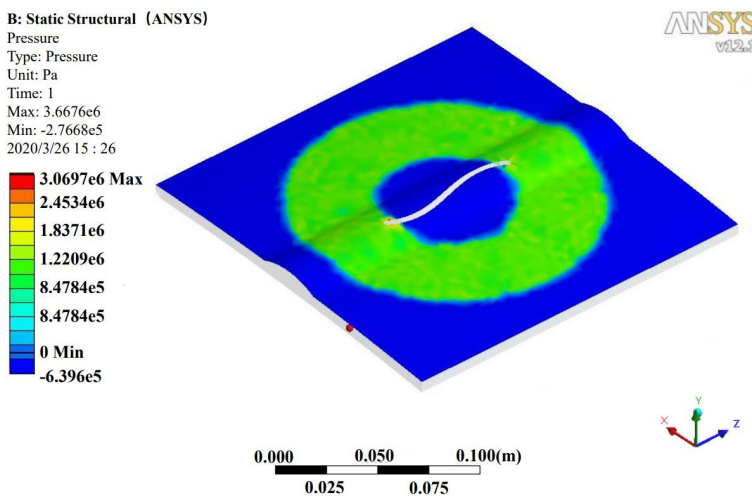

Fig. 11. Pressure of the sealing surface of the liquid reservoir sealing method

As can be seen from Figs. 10 and 11, the conventional sealing method only uses the deformation of the rubber material to adapt to the concave and convex fluctuation of the sealing surface, resulting in a strong stress concentration area at the convex part of the weld, which becomes an obvious high-pressure area, while the annular area outside the weld is a low-pressure area, which has a great potential safety hazard.

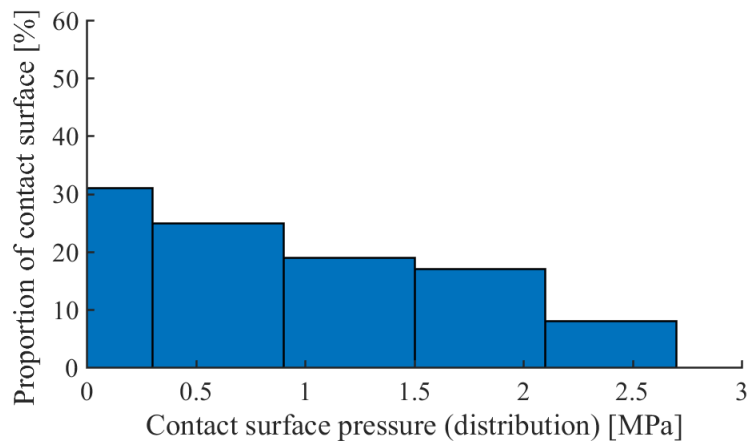

Fig. 12. Pressure section of conventional sealing method 
In the new sac-sealing device, the sealing gasket forms a pressure-sensitive contact sealing zone (0.9 $\mathrm{MPa}$ ) around the leak point around the crack, and no obvious low-pressure annular region appears. The pressure distribution of the sealing surface was counted to obtain the results of Figs. 12 and 13.

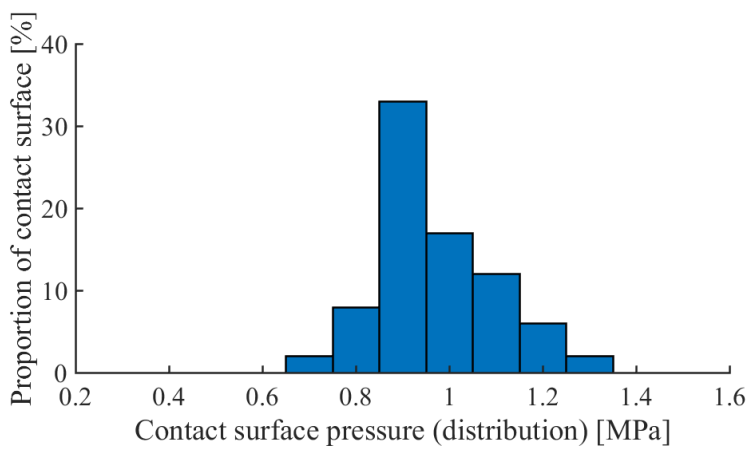

Fig. 13. Pressure section of sealing surface of liquid reservoir

The pressure distribution of the contact surface affects the working effect of the plugging device. Assuming that more than $90 \%(0.9 \mathrm{MPa})$ of the plugging load is the effective plugging pressure, a large number of low-pressure (less than $0.9 \mathrm{MPa}$ ) areas appear on the contact surface of the conventional plugging method, reaching $56 \%$ of the total area, and the effective plugging surface is only about $44 \%$. In the new method of sealing the outer capsule, the effective sealing area reaches nearly $90 \%$, mainly distributed between 0.9 and $1.2 \mathrm{MPa}$, and the load is evenly transmitted to the sealing working surface.

\subsection{Seal Thickness Analysis}

The thickness of the gasket is also a key factor affecting the sealing performance, which determines the sealing performance of the sealing device. Based on the above model, the two plugging methods are further simulated and analysed with the thickness of the gasket as a variable. The results obtained are shown in Fig. 14.

The conventional plugging methods use the material properties of rubber pads to accommodate irregular sealing surfaces around leak points. When the thickness is small, the adaptability of the gasket is poor, and the proportion of forming an effective sealing surface is also low. As the thickness of the gasket increases, its self-adaptation ability gradually increases, and the proportion of the effective sealing surface increases. When the thickness is $24 \mathrm{~mm}$, the peak value $(76 \%)$ is reached. Due to the lack of corresponding constraints on the outer side of the gasket cylinder, the rubber material is forced to flow out from the side, resulting in a decrease in the bearing capacity of the rubber material and a low-stress phenomenon. As the thickness increases, the phenomenon becomes more apparent, and the proportion of the effective pressure region is also reduced.

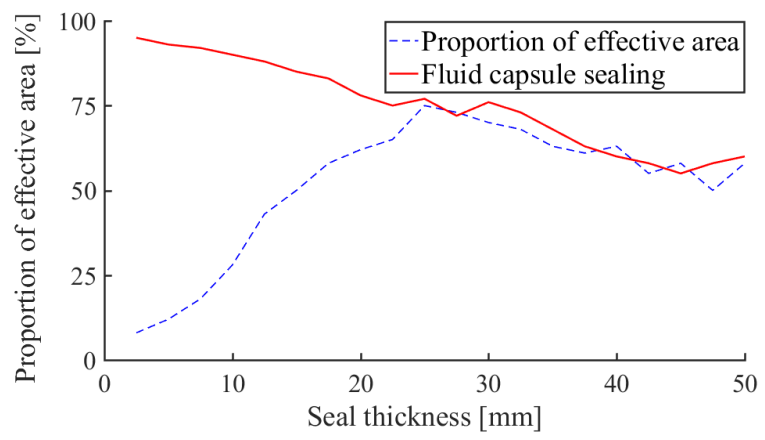

Fig. 14. Product ratio curve distribution of effective sealing surface under different sealing surface thickness

The novel capsular plugging method utilizes the fluidity of the liquid in the chamber to convert the load on the housing into fluid pressure and load it on the gasket. During the sealing process, the deformation of the thickness direction of the gasket is relatively uniform, which overcomes the shortage of the adaptability of the gasket in the conventional sealing method, and the effective pressure region formed is improved. When the thickness is small, the effective area ratio of the plugging reaches about 90 $\%$. As the thickness increases, the sac-sealing method also shows the same proportion of decline. Similar results were obtained in simulation analysis under different pressures.

\section{CONCLUSIONS}

In this paper, the finite element model is established, and ANSYS is used to simulate and analyse the installation and sealing process of the conventional top pressure plugging device and the proposed new external sealing device.

1. During the installation process, when analysing the flow field velocity on both sides of the crack, it was found that only a small part of the material flowed out from the gap, and most of the material flowed out from the diversion channel, which was effectively recovered. When analysing the thickness of the gap, it was found that when the thickness of the gap is small, the installation resistance of the sac plugging method is smaller. 
2. During the plugging process, an analysis of the pressure distribution around the leak found that compared with the traditional plugging method, the effective plugging area was increased to nearly $90 \%$, and the pressure distribution was more uniform. The analysis of the thickness of the gasket found that the smaller the thickness, the stronger the adaptability of the sac plugging method, the uniform shape change of the gasket, and the larger the effective sealing area and the longer the life.

\section{ACKNOWLEDGEMENTS}

The work described in this article is supported by the Research Project Supported by Shanxi Scholarship Council of China (2020-110) the Key Technology Research and Development Program of China's Shanxi Province (201603D321117) and the Natural Science Foundation of China's Shanxi Province (2013011026-2), which is mainly reflected in the innovation of plugging device. Moreover, the author sincerely thanks Professor Wu Wenge of North University of China for his critical discussion and reading in the process of manuscript preparation.

\section{REFERENCES}

[1] Liu, Y., Cheng, Q.L., Gan, Y.F., Wang, Y.X., Li, Z.D., Zhao, J. (2019). Multi-objective optimization of energy consumption in crude oil pipeline transportation system operation based on exergy loss analysis. Neurocomputing, vol. 332, p. 100-110, D0l:10.1016/j.neucom.2018.12.022.

[2] Cheng, Q.L., Zheng, A.B., Yang, L., Pan, C.L., Sun, W., Liu, Y. (2018). Studies on energy consumption of crude oil pipeline transportation process based on the unavoidable exergy loss rate. Case Studies in Thermal Engineering, vol. 12, p. 8-15, D0I:10.1016/j.csite.2018.02.005.

[3] Xu, H.F., Bbosa, B., Pereyra, E., Volk, M., Manna, M.S. (2018). Oil transportation in pipelines with the existence of ice. Journal of Loss Prevention in the Process Industries, vol. 56, p. 137146, D0I:10.1016/j.jp.2018.08.015.

[4] Yang, S., Jeon, K., Kang, D.J., Han, C.H. (2017). Accident analysis of the Gumi hydrogen fluoride gas leak using CFD and comparison with post-accidental environmental impacts. Journal of Loss Prevention in the Process Industries, vol. 48, p. 207-215, D0l:10.1016/j.jp.2017.05.001.

[5] Liu, Q., Yu, H.Y., Zhu, G.C., Wang, P.B., Song, S.Y. (2020). Investigation on leakage cause of oil pipeline in the west oilfield of China. Engineering Failure Analysis, vol. 113, art. ID 104552, DOI:10.1016/j.engfailanal.2020.104552.

[6] Jia, Z.G., Ho, S.-C., Li, Y., Kong, B., Hou, Q.M. (2019). Multipoint hoop strain measurement-based pipeline leakage localization with an optimized support vector regression approach. Journal of Loss Prevention in the Process Industries, vol. 62, art. ID 103926, DOI:10.1016/j.jlp.2019.103926.

[7] Wang, C.L., Li, Y.X., Teng, L., Gu, S.W., Hu, Q.H., Zhang, D.T., Ye, X., Wang, J.H. (2019). Experimental study on dispersion behavior during the leakage of high-pressure $\mathrm{CO}_{2}$ pipelines. Experimental Thermal and Fluid Science, vol. 105, p. 77-84, D0I:10.1016/j.expthermflusci.2019.03.014.

[8] Chaudhari, P., Zerpa, L.E., Sum, A.K. (2018). A correlation to quantify hydrate plugging risk in oil and gas production pipelines based on hydrate transportability parameters. Journal of Natural Gas Science and Engineering, vol. 58, p. 152-161, D0I:10.1016/j.jngse.2018.08.008.

[9] Qu, Z., Wang, Y., Yue, H., An, Y., Wu, L., Zhou, W., Wang, H., Su, Z., Li, J., Zhang, Y, Wang, L., Yang, X., Cai, Y., Yan, D. (2017). Study on the natural gas pipeline safety monitoring technique and the time-frequency signal analysis method. Journal of Loss Prevention in the Process Industries, vol. 47, p. 1-9, DOI:10.1016/j.jlp.2017.02.016.

[10] An, Y., Wang, X., Yue, B., Wu, L., Qu, Z., Yue, H., Yan, D. (2018). Natural gas pipeline safety monitoring technique based on chaotic characteristics of the detected signals. Process Safety and Environmental Protection, vol. 118, p. 279-284, DOI:10.1016/j.psep.2018.07.007.

[11] Wang, W., Guo, J., Fan, J., Zhang, S., Zhu, X., Wang, C. (2020). Research on the proportional-integral-derivative synchronous control method of the marine spherical isolation plug in the rotation process. Proceedings of the Institution of Mechanical Engineers, Part M: Journal of Engineering for the Maritime Environment, vol. 234, no. 4, p. 810-819, DOI:10.1177/1475090220913704.

[12] Park, S., Kim, H. (2014). Structural analysis of gas pipeline repaired by carbon fiber composite materials. Journal of The Korean Institute of Gas, vol. 18, no. 2, p. 62-68, D0l:10.7842/ kigas.2014.18.2.62. (in Korean)

[13] Zhang, K., Huang, H., Duan, M.L., Hong, Y., Estefen, S.F. (2017). Theoretical investigation of the compression limits of sealing structures in complex load transferring between subsea connector components. Journal of Natural Gas Science and Engineering, vol. 44, p. 202-213, D0l:10.1016/j. jngse.2017.03.034.

[14] Kumar, R., Banerjee, S., Banik, A., Bandyopadhyay, T.K., Naiya, T.K. (2017). Simulation of single phase non-Newtonian flow characteristics of heavy crude oil through horizontal pipelines. Petroleum Science \& Technology, vol. 35, no. 6, p. 615-624, DOl:10.1080/10916466.2016.1266365.

[15] Koc, P. (2019). An exacting wall-penetration pipe analysis. Strojniški vestnik - Journal of Mechanical Engineering, vol. 65, no. 3, p. 189-197, D0I:10.5545/sv-jme.2018.5651.

[16] Gupta, P., Zan, T.T.T., Wang, M., Dauwels, J., Ukil, A. (2018). Leak detection in low-pressure gas distribution networks by probabilistic methods. Journal of Natural Gas Science and Engineering, vol. 58, p. 69-79, Dol:10.1016/j. jngse.2018.07.012.

[17] An, Y., Wang, X.C., Yue, B., Qu, Z.G., Wu, L.Q., Chu, R.G. (2019). Compensation of sound velocity variation based on resampling algorithm for natural gas pipeline safety monitoring. Measurement, vol. 148, art. ID 106942, D0l:10.1016/j. measurement.2019.106942. 
[18] Araújo, M.V., Neto, S.R.F, Lima, A.G.B., Luna, F.D.T. (2015) Hydrodynamic study of oil leakage in pipeline via CFD. Advances in Mechanical Engineering, vol. 6, art. ID. 170178, DOI:10.1155/2014/170178.

[19] Sievers, J., Heckmann, K., Pallas-Moner, G., Lerchl, G. (2015). Structural mechanical and thermal hydraulic aspects on the behavior of crack like leaks in piping. Progress in Nuclear Energy, vol. 84, p. 18-23, D0l:10.1016/j.pnucene.2015.03.023.

[20] Hasegawa, K., Li, Y.S., Lacroix, V., Mares, V. (2020). Application scope of limit load criterion for uctile material pipes with circumferentially external cracks. Journal of Pressure Vessel Technology, vol. 142, no. 3, p. 031506 , DOI:10.1115/1.4046055.

[21] Boujleben, A., Ibrahimbegovic, A., Lefrançois, E. (2020). An efficient computational model for fluid-structure interaction in application to large overall motion of wind turbine with flexible blades. Applied Mathematical Modelling, vol. 77, p. 392-407, DOl:10.1016/j.apm.2019.07.033.

[22] Mohammadi, N., Asadi, H., Aghdama, M.M. (2019). An efficient solver for fully coupled solution of interaction between incompressible fluid flow and nanocomposite truncated conical shells. Computer Methods in Applied Mechanics and Engineering, vol. 351, p. 478-500, D0l:10.1016/j. cma.2019.03.044.

[23] Bohorquez, J., Alexander, B., Simpson, A.R., Lambert, M.F. (2020). Leak detection and topology identification in pipelines using fluid transients and artificial neural networks. Journal of Water Resources Planning and Management, vol. 146, no. 6, p. 04020040, D0l:10.1061/(ASCE)WR.1943-5452.0001187.

[24] Bbosa, B., Ozbayoglu, E., Volk, M. (2019). Experimental investigation of hydrate formation, plugging and flow properties using a high-pressure viscometer with helical impeller. Journal of Petroleum Exploration and Production Technology, vol. 9, p. 1089-1104, D0l:10.1007/s13202-018-0524-6.

[25] Jia Z.G., Ren, L., Li, H.N., Ho, S.C., Song, G.B.. (2015). Experimental study of pipeline leak detection based on hoop strain measurement. Structural Control \& Health Monitoring, vol. 22, p. 799-812, D0l:10.1002/stc.1718.

[26] Guedri, A, Belyamna, M.A., Boutelidja, R., Djebbar, Y. (2019). Interpretation of the effect of hydrostatic test in components working under pressure. Engineering Failure Analysis, vol. 106, art. ID 104174, D0I:10.1016/j.engfailanal.2019.104174.

[27] Amara, M., Bouledroua, O., Hajd Meliani, M., Azari, Z., Tahar Abbess, M., Pluvinage, G., Bozic, Z. (2019). Effect of corrosion damage on a pipeline burst pressure and repairing methods. Archive of Applied Mechanics, vol. 89, p. 939-951. DOl:10.1007/s00419-019-01518-z.

[28] Shen, Y.P., Lin, Y.R., Li, P., Fu, Y.J., Wang, Y.Q. (2020). Simulation and detection leakage of underground water pipeline by ground penetrating radar. Journal of Testing and Evaluation, vol. 48, no. 3, p. 2003-2027, D0l:10.1520/ JTE20190181.

[29] Raafat, E., Nassef, A., El-hadek, M., El-Megharbel, A. (2019). Fatigue and thermal stress analysis of submerged steel pipes using ANSYS software. Ocean Engineering, vol. 193, art. ID 106574, DOl:10.1016/j.oceaneng.2019.106574.

[30] Jiao, Z., Shuai, J. (2014). A cyclic internal pressure characteristics analysis of long-distance transmission pipelines. Petroleum Science and Technology, vol. 32, no. 1, p. 61-67, D0I:10.1080/10916466.2011.582064.

[31] Lu, H.F., Ma, G.G., Li, X.T., Wu, S.J. (2018). Stress analysis of LNG storage tank outlet pipes and flanges. Energies, vol. 11, no. 4, art. ID 877, D0I:10.3390/en11040877.

[32] Sohaib, M., Islam, M., Kim, J., Jeon, D.-C., Kim, J.-M.. (2019). Leakage detection of a spherical water storage tank in a chemical industry using acoustic emissions. Applied Sciences, vol. 9, no. 1, art. ID 196, D0l:10.3390/app9010196.

[33] Quan, D., Cardiff, P., Murphy, N., Ivankovic, A. (2018). Damage behaviour of nano-modified epoxy adhesives subject to high stress constraint. The Journal of Adhesion, vol. 94, no. 5, p. 387-405, DOI:10.1080/00218464.2017.1279542. 